\title{
Some Applieations of Cryogenics to High Speed \\ Ground Transportation
}

U.S. EPARTMENT OF COMMERCE National Bureau $Q C$ of $100 \mathrm{Js}$

U5753 no. 635 1973 4.2 ) 


\section{NATIONAL BUREAU OF STANDARDS}

The National Bureau of Standards ${ }^{1}$ was established by an act of Congress March 3, 1901. The Bureau's overall goal is to strengthen and advance the Nation's science and technology and facilitate their effective application for public benefit. To this end, the Bureau conducts research and provides: (1) a basis for the Nation's physical measurement system, (2) scientific and technological services for industry and government, (3) a technical basis for equity in trade, and (4) technical services to promote public safety. The Bureau consists of the Institute for Basic Standards, the Institute for Materials Research, the Institute for Applied Technology, the Center for Computer Sciences and Technology, and the Office for Information Programs.

THE INSTITUTE FOR BASIC STANDARDS provides the central basis within the United States of a complete and consistent system of physical measurement; coordinates that system with measurement systems of other nations; and furnishes essential services leading to accurate and uniform physical measurements throughout the Nation's scientific community, industry, and commerce. The Institute consists of a Center for Radiation Research, an Office of Measurement Services and the following divisions:

Applied Mathematics - Electricity - Mechanics - Heat - Optical Physics Linac Radiation 2 - Nuclear Radiation 2 - Applied Radiation ${ }^{2}$ - Quantum Electronics " Electromagnetics $"$ - Time and Frequency ${ }^{3}$ — Laboratory Astrophysics : - Cryogenics ${ }^{3}$.

THE INSTITUTE FOR MATERIALS RESEARCH conducts materials research leading to improved methods of measurement, standards, and data on the properties of well-characterized materials needed by industry, commerce, educational institutions, and Government; provides advisory and research services to other Government agencies; and develops, produces, and distributes standard reference materials. The Institute consists of the Office of Standard Reference Materials and the following divisions:

Analytical Chemistry-Polymers-Metallurgy-Inorganic Materials-Reactor Radiation-Physical Chemistry.

THE INSTITUTE FOR APPLIED TECHNOLOGY provides technical services to promote the use of available technology and to facilitate technological innovation in industry and Government; cooperates with public and private organizations leading to the development of technological standards (including mandatory safety standards), codes and methods of test; and provides technical advice and services to Government agencies upon request. The Institute also monitors NBS engineering standards activities and provides liaison between NBS and national and international engineering standards bodies. The Institute consists of a Center for Building Technology and the following divisions and offices:

Engineering and Product Standards-Weights and Measures-Invention and Innovation-Product Evaluation Technology-Electronic Technology-Technical Analysis-Measurement Engineering-Building Standards and Code Services ${ }^{4}$ _Housing Technology ${ }^{4}$-Federal Building Technology ${ }^{4}$-Structures, Materials and Life Safety ${ }^{4}$-Building Environment ${ }^{4}$ - Technical Evaluation and Application ${ }^{4}$-Fire Technology.

THE INSTITUTE FOR COMPUTER SCIENCES AND TECHNOLOGY conducts research and provides technical services designed to aid Government agencies in improving cost effectiveness in the conduct of their programs through the selection, acquisition, and effective utilization of automatic data processing equipment; and serves as the principal focus within the executive branch for the development of Federal standards for automatic data processing equipment, techniques, and computer languages. The Center consists of the following offices and divisions:

Information Processing Standards-Computer Information-Computer Services - Systems Development-Information Processing Technology.

THE OFFICE FOR INFORMATION PROGRAMS promotes optimum dissemination and accessibility of scientific information generated within NBS and other agencies of the Federal Government; promotes the development of the National Standard Reference Data System and a system of information analysis centers dealing with the broader aspects of the National Measurement System; provides appropriate services to ensure that the NBS staff has optimum accessibility to the scientific information of the world, and directs the public information activities of the Bureau. The Office consists of the following organizational units:

Office of Standard Reference Data-Office of Technical Information and Publications-Library-Office of International Relations.

\footnotetext{
1 Headquarters and Laboratories at Gaithersburg, Maryland, unless otherwise noted; mailing address Washington, D.C. 20234

2 Part of the Center for Radiation Research.

${ }^{3}$ Located at Boulder, Colorado 80302.

- Part of the Center for Building Technology.
} 
V.D. Arp

A.F. Clark

T.M. Flynn

\section{Cryogenics Division}

Institute for Basic Standards

National Bureau of Standards

Boulder, Colorado 80302

NBS Technical notes are designed to supplement the Bureau's regular publications program. They provide a means for making availahle scientific data that are of transient or limited interest. Technical Notes may be listed or referred to in the open literature.

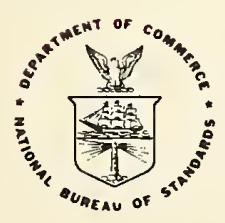

U.S. DEPARTMENT OF COMMERCE, Frederick B. Dent, Secretary NATIONAL BUREAU OF STANDARDS, Richard W. Roberts, Director Issued February 1973 
National Bureau of Standards Technical Note 635

Nat. Bur. Stand. (U.S.) Tech. Note 635, 29 pages (February 1973) CODEN: NBTNAE

For sale by the Superintendent of Documents, U.S. Government Printing Office, Washington, D. C. 20402 (Order by SI Calaloy No. C13.46:635) 


\section{CONTENTS}

Page

1. INTRODUCTION ................. 1

2. WAYS OF LEVITATION ............ 5

2. 1 Air Cushion ............ . . 5

2. 2 Magnetic Levitation/Suspension ....... 5

2.2.1 Attraction Between Electromagnets and Steel Rails....... . . 6

2.2. 2 Repulsion Between Permanent Magnets . 8

2.2.3 Repulsion Between a Superconducting

Train Magnet and Conductors in the

Guideway . . . . . . . . .

3. STATE-OF-THE-ART IN THE U.S. OF MAGNETIC SUSPENSION . . . . . . . . . . . . . 14

4. FOREIGN PROGRAM PLANS ......... 15

5. PROPULSION ................. . . 17

6. SOME CRYOGENIC TECHNICAL PROBLEMS . . . . 17

6. 1 Helium Refrigeration .......... 19

6.2 Materials .............. 19

7. FUTURE DEVELOPMENT . . . . . . . . . 20

8. REFERENCES .............. . . 23 

Vincent D. Arp, Alan F. Clark and Thomas M. Flynn

The current status (December 1972) of worldwide research on high speed ground transportation techniques is reviewed. Particular attention is given to studies of magnetic levitation using superconducting magnets, including comparison with alternative magnetic techniques and with air suspension systems. Superconducting levitation appears to be a strong contender in the U.S. Department of Transportation hopes to select in the late 1970's the best of the possible levitation techniques for subsequent advanced development. Cryogenic engineering research needed in support of major development of a superconducting levitated system is identified.

Key words: Levitation; magnetic suspension; materials fatigue data; refrigeration; superconducting magnets; transportation.

\section{INTRODUCTION}

The status of transportation in this country was summarized by Senator Vance Hartke (1972), Chairman of the Senate Surface Transportation Subcommittee: "We have regretably allowed our transportation network to grow in an unplanned, uncoordinated, fashion. We have expended too little effort in integrating - fusing - the development of our various modes of transportation. We have given too little thought and attention to how transportation might be planned to structure regional or national development in a practical manner. We have, in short, created a crisis."

The changing balance of transportation use in this country is seen directly in table 1 . 
Table 1. Intercity Passenger Traffic

\section{Year \\ $1950 \quad 1955 \quad 1960 \quad 1965 \quad 1969$}

Lift to Drag Percent of intercity passenger-miles Ratio*

$\begin{array}{lcccccc}\text { Private auto } & 20 & 86 & 89 & 90 & 89 & 87 \\ \text { Airway } & 20 & 2.0 & 3.2 & 4.3 & 6.3 & 9.8 \\ \begin{array}{l}\text { Bus (excludes } \\ \quad \text { schoolbus) }\end{array} & 20 & 5.2 & 3.6 & 2.5 & 2.6 & 2.2 \\ \begin{array}{l}\text { Railroad } \\ \text { Canal Barge }\end{array} & 150 & 6.4 & 4.0 & 2.8 & 1.9 & 1.1 \\ & 1000 & 0.23 & 0.24 & 0.34 & 0.34 & 0.34\end{array}$

An index of merit, the ratio of the weight of the vehicle to the force required to keep it moving at a given speed.

Mass ground transport, and railroads in particular, have suffered dramatic decreases in passenger miles of travel, while air travel has risen correspondingly. At the same time, auto transport has only just about held constant on a percentage basis, probably due in part to the 60 billion dollar Federal Highway Assistance Program, which is now $77 \%$ complete. Airlines have been assisted by local, state, and federal support. Rail travel, on the other hand, has fallen in the quantity of passenger train-miles available. In principle, however, rail service should be about the most efficient way of moving people and goods, as judged by the lift-to-drag ratios for various types of transport shown in figure I (Gudenjahn and Wipf, 1971).

It is important to note that successful operation of the high speed Tokaido Line in Japan has resulted in measurable decrease in the 


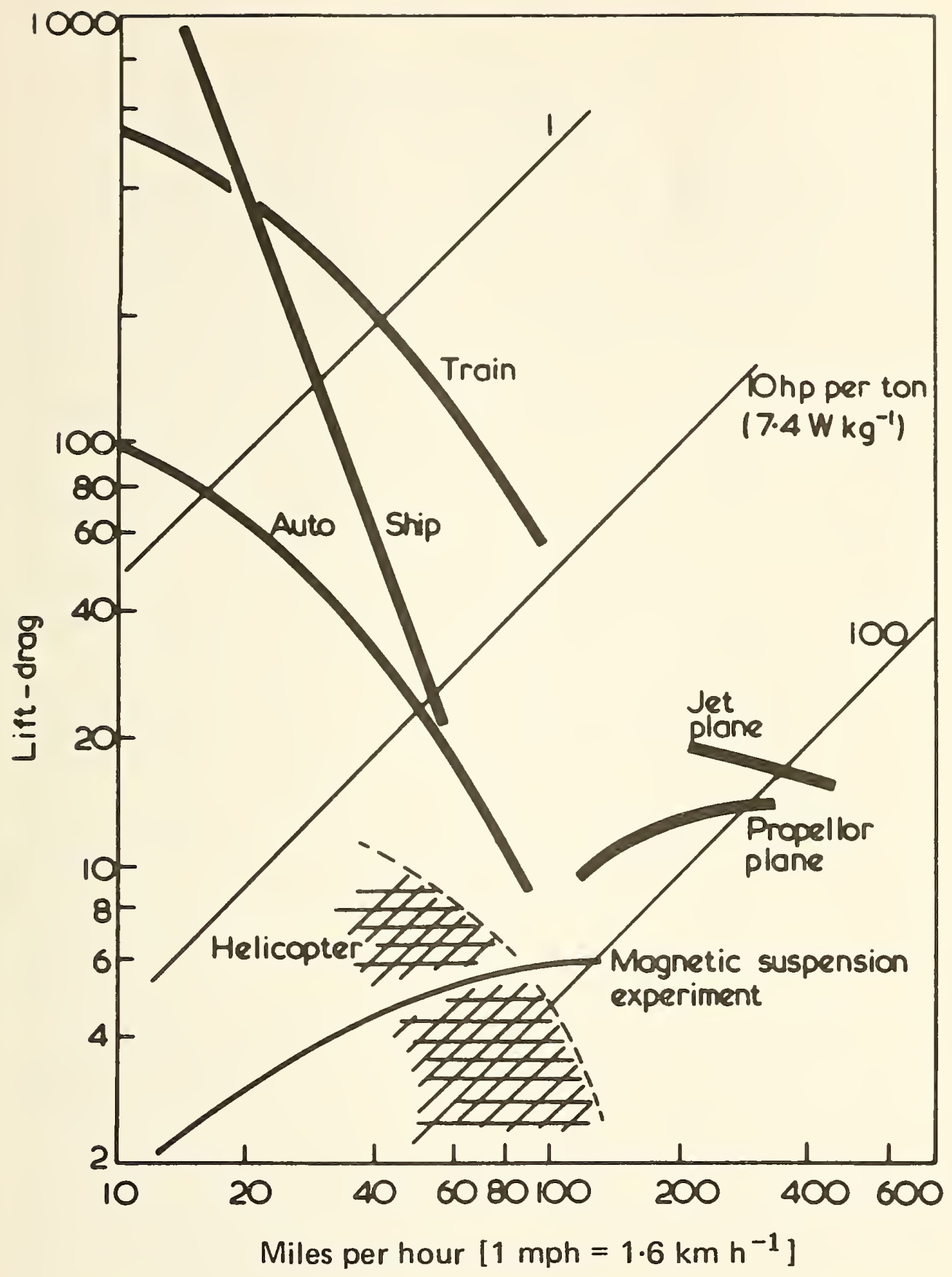

Figure 1. Lift to drag ratios as a function of speed for various types of transportation (Guderjahn and Wipf, 1971). 
localized air traffic. In recognition of these and related facts, the Office of Research, Development and Demonstration (ORDD) $*$ in the Federal Railway Administration (FRA) is investigating new methods of ground transportation, with speeds of up to $500 \mathrm{mph}(800 \mathrm{~km} / \mathrm{hr})$ under consideration for intercity travel. However, even at speeds above about 125 to $150 \mathrm{mph}(200$ to $250 \mathrm{~km} / \mathrm{hr}$ ) wheels become impractical. This is the case because the suspension system, upon which the vehicle weight is concentrated, becomes incapable of absorbing or accommodating to the high frequency shocks from residual irregularities in the wheels, roadbed, or track. Accordingly, there is no question that contact between the train and the track must be eliminated by either air cushion or magnetic suspension for speeds in the range of 250 to $500 \mathrm{mph}(400$ to $800 \mathrm{~km} / \mathrm{hr}$ ) which are becoming a national goal for intercity ground transportation. Air cushion technology currently has a development lead, but magnetic suspension potentially has a much higher efficiency and lower adverse environmental impact.

Magnetic levitation, floating one magnet above another on the simple principle that like poles repel one another, has become really practical and dependable for very large magnets only in the last few years with the advent of workable superconductors. Superconductivity is found only at very low temperatures, and this forges an indispensable link between cryogenics and transportation. The remainder of this paper focuses primarily on the essential role of cryogenics in magnetic levitation. However, if a cryogenic system were an integral part of a train for levitation purposes, it might be expedient to exploit the benefits of cryogenics for superconducting generators and propulsion motors as well. This latter topic is touched upon but briefly.

* formerly known as the Office of High Speed Ground Transportation (OHSGT). 


\section{WAYS OF LEVITATION}

\subsection{Air Cushion}

The ORDD of the Federal Railway Administration of DoT has sponsored the development of Tracked Air Cushion Vehicles (TACVs) since 1967, with maximum speeds targeted at $300 \mathrm{mph}(500 \mathrm{~km} / \mathrm{hr})$, limited by vehicle wind resistance. The TACV is both supported and guided in a concrete guideway by air cushions provided by on-board compressors.

Outside of the USA, England and France have major demonstration programs underway on TACV, with tentative plans for usage in airport shuttle service. The top speed reached by the French propellerdriven Aerotrain was $265 \mathrm{mph}(430 \mathrm{~km} / \mathrm{hr})$ on January 22, 1969, but its noisy propeller creates a severe environmental impact problem. At present, TACV research enjoys a comfortable lead on magnetic vehicle levitation research. Its potential disadvantage as compared to superconducting magnetic levitation includes: (1) high track cost because of the small vehicle to roadway clearance (1 to $2 \mathrm{~cm}$ ), and (2) the necessity for a heavy and somewhat noisy on-board mechanical power source to provide the air flow.

\subsection{Magnetic Levitation/Suspension}

Magnetic fields can be employed for magnetic "cushions" analogous to the way that air is used to support and guide an air cushion vehicle.

Proposals embodying this general concept date back to the early 1900's, but have been given serious attention only in the past few years as high field superconductivity has come of age. The required magnetic fields can be generated by permanent magnets, electromagnets (generally 
superconducting), or eddy currents in a conducting sheet or loop due to relative motion with an opposing magnet. Often, some sort of magnetic propulsion by linear electric motors is considered in addition to the magnetic levitation, and it is possible in principle to use the same magnets for both operations (Richards and Tinkham, 1972). The various possible levitation systems are outlined in table 2 , with one exception: Clark (1971) has suggested that to conserve rights-of-way, the track might be built in conjunction with a superconducting power line to provide a track-based magnetic field which could levitate either a passive eddy current shield on the bottom of the vehicle or a superconducting magnet on board the vehicle. It is not certain that the possibly disparate requirements of power transmission and vehicle levitation could simultaneously be satisfied, and it appears that tests of this suggestion will have to wait for further superconducting power line development.

\subsubsection{Attraction Between Electromagnets and Steel Rails}

In the attraction system, a servo-controlled electromagnet is carried on the vehicle. The attraction between the electromagnet and steel guide rails provides lift and guidance. A gap of about 0.5 in (12 mm) can be maintained between magnet and rail at a power expenditure of about $1 \mathrm{~kW}$ per metric ton of suspended weight. This small gap has to be monitored and controlled by a very fast acting and reliable servo-system, since this suspension technique is inherently unstable.

Two attractive-rail test vehicle programs are being explored by the German Ministry of Transport. In the system developed by Krauss-Maffei (KM), the gap is held nearly constant and the unavoidable irregularities of the guide rails must be cushioned by a secondary suspension system. In the Messerschmitt-Bolkow-Blohm 
Table 2. Features of Various Suspension Systems

\begin{tabular}{|c|c|c|}
\hline \multirow{2}{*}{$\begin{array}{c}\text { Roadbed Magnetic } \\
\text { Field }\end{array}$} & \multicolumn{2}{|c|}{ Vehicle Magnetic Field } \\
\hline & $\begin{array}{l}\text { Permanent } \\
\text { Magnets }\end{array}$ & $\begin{array}{c}\text { Electromagnets } \\
\text { (generally superconducting) }\end{array}$ \\
\hline $\begin{array}{l}\text { Permanent } \\
\text { Magnets } \\
\text { (very expensive; } \\
\text { difficult to keep } \\
\text { track clean). }\end{array}$ & $\begin{array}{l}\text { Small lifting force. } \\
\text { Small vehicle clearance. } \\
\text { Stability problems re- } \\
\text { quire additional } \\
\text { control. } \\
\text { Very low magnetic drag } \\
\text { (Pohlgreon, 1966). }\end{array}$ & $\begin{array}{l}\text { Would provide greater lift } \\
\text { and clearance than the all } \\
\text { permanent magnet system. }\end{array}$ \\
\hline $\begin{array}{l}\text { Induced Eddy } \\
\text { Currents in Con- } \\
\text { ducting Sheets or } \\
\text { Loops. }\end{array}$ & $\begin{array}{l}\text { (Same as above). } \\
\text { (Has never been } \\
\text { seriously proposed). }\end{array}$ & $\begin{array}{l}\text { Can support high loads with } \\
\text { high clearances at speeds } \\
\text { above about } 40 \text { to } 80 \mathrm{~km} / \mathrm{h} \mathbf{r} \\
\text { using superconducting } \\
\text { magnets. } \\
\text { Being studied in USA, Japan, } \\
\text { Germany, Canada. }\end{array}$ \\
\hline $\begin{array}{l}\text { High Permeability } \\
\text { Magnetic Rail. }\end{array}$ & $\begin{array}{l}\text { Impossible: inherently } \\
\text { unstable and uncon- } \\
\text { trollable attraction } \\
\text { between the magnet } \\
\text { and the rail. }\end{array}$ & $\begin{array}{l}\text { Fail-safe operation is } \\
\text { difficult to achieve. } \\
\text { Two test trains are running } \\
\text { in Germany, using conven- } \\
\text { tional electromagnets. } \\
\text { Small vehicle clearance. } \\
\text { Very low magnetic drag. } \\
\text { Inherently unstable but can } \\
\text { be controlled. }\end{array}$ \\
\hline
\end{tabular}


(MBB) system, the gap is allowed to vary, and no secondary suspension is used. An additional difference between the two schemes is that Krauss-Maffei has dispensed with the vertical steel rail and derives both lift and guidance from each electromagnet. Schematic drawings are given in figure 2. Both of the German vehicles achieved successful demonstration in barely one year's time, and are impressive evidence that the technique is within the state-of-the-art. Because of relatively short lengths of test tracks, top speeds to date have been about $60 \mathrm{mph}$ $(100 \mathrm{~km} / \mathrm{hr})$. The track must be constructed and maintained to very tight tolerance in order to obtain good ride quality at $300 \mathrm{mph}(500$. $\mathrm{km} / \mathrm{hr}$ ). Because of the inherent instability in this type of suspension, however, the feedback-controlled levitation system must have a high degree of redundancy and protective circuitry built into it to assure safe operation in the event of every conceivable possible component failure or failures. The tests in Germany are being watched very carefully, since the system has had no major development problems to date. Whether appropriate redundancies can be built into the control system to guarantee safe daily operation is not known at this time.

\subsubsection{Repulsion Between Permanent Magnets}

The recent development of rare-earth cobalt permanent magnets possessing high intrinsic coercivity gives new impetus to the old idea of using the repulsion between like poles to support and guide a vehicle. This technique is by now quite well known, having been demonstrated years ago by Westinghouse in a single-passenger vehicle (Kerr and Lynn, 1961) and lately by Hitachi in the small-scale magnetically suspended train displayed at EXPO 70. Pre-rare-earth cobalt materials provided gaps of less than a centimeter and were subject to selfdemagnetization. The advantages of permanent magnets for suspension 
THE ELECTROMAGNETS ON THE TRAIN ARE ATTRACTED TO AN IRON PLATE IN THE GUIDEWAY

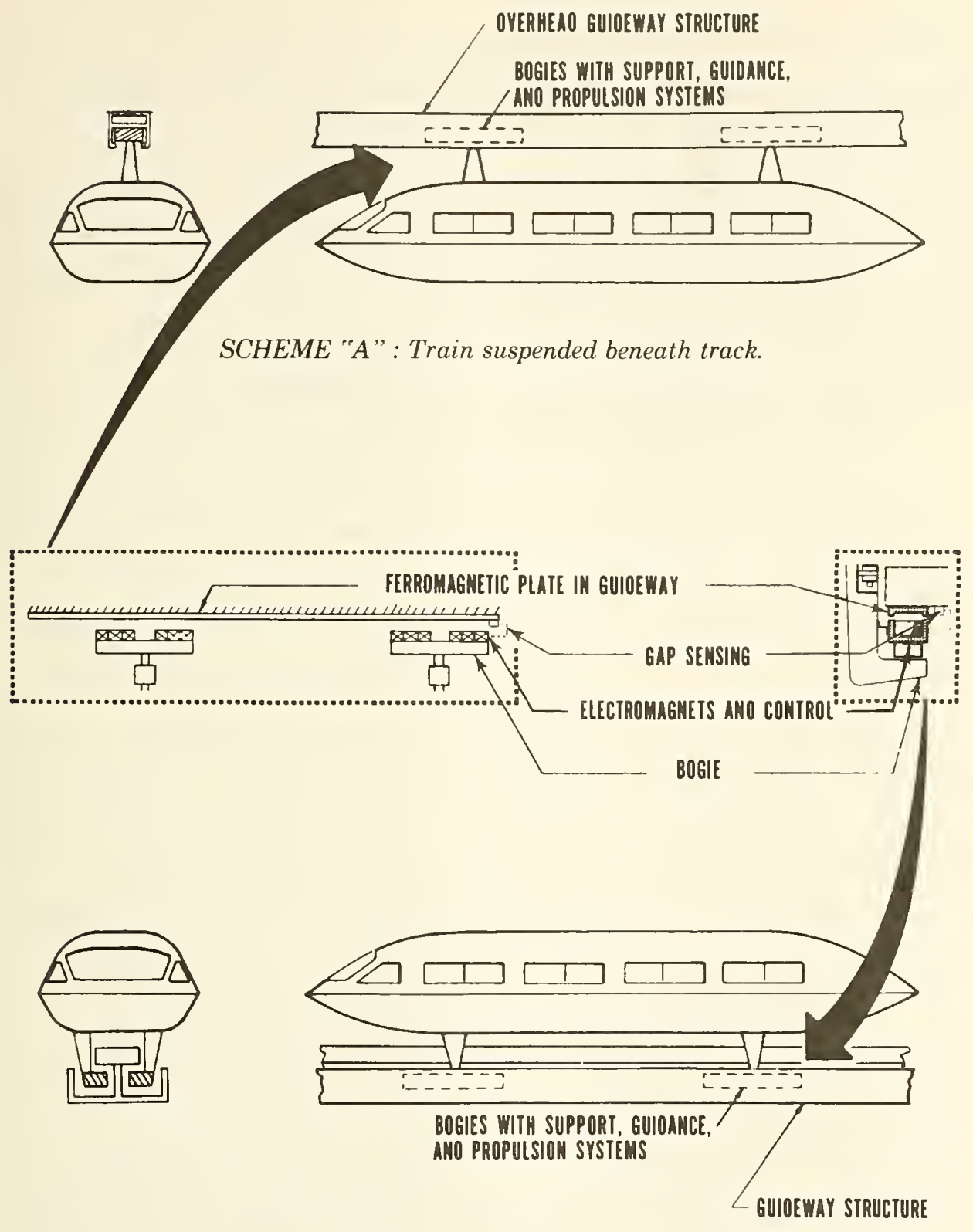

SCHEME "B" - Train levitated above track.

Figure 2. Schematic diagram of two possible attractive-suspension systems. 
are that there is no induced drag and no power is required for levitation. The cost of the guideway is probably the most overwhelming drawback. Estimates range from $\$ 4.5$ to $\$ 9$ million per kilometer, and this is based on a very optimistic projection of ultimate $\mathrm{RCo}_{5}$ magnet costs of $\$ 33 / \mathrm{kgm}$, or little more than the cost of the raw materials. Finally, the problem of maintaining a clean track, smooth and free of magnetic litter, would be significant.

2.2.3 Repulsion Between a Superconducting Train Magnet and Conductors in the Guideway

The first suggestion for vehicle levitation with superconducting magnets came from Powell in 1963, subsequently improved and made more detailed by he and Danby in 1966. Later they developed the "null flux" suspension idea. The history of this development, along with a concise technical summary, is presented in their 1971 paper.

As superconducting magnets began to prove themselves in high energy physics applications, more attention was given to this magnetic levitation. Consideration was given to magnetic suspension for a high speed rocket test sled and other studies appeared by Guderjahn and Wipf (1969) at Atomics International, and Coffey, Barbee, and Chilton (1969) at the Stanford Research Institute (SRI). Guderjahn and Wipf (1971) and Powell and Danby (1971) have since published excellent reviews. Richards and Tinkham (1972) have summarized technical features of magnetic lift, drag, and propulsion systems.

The essence of the superconductive repulsion system is the use of superconducting magnets in the vehicle which induce eddy currents in the aluminum guide-way when the vehicle is moving. These guideway currents react with the moving magnetic field in the vehicle to 
produce a repulsive supporting force. Guidance is obtained by the same techniques and by designing the aluminum guideways to produce lateral forces on the vehicle. It may prove possible to shape the guideway in such a way that the same superconducting magnet in the vehicle can be used for both suspension and guidance. Two schemes are shown in figure 3 .

An important feature of the eddy-current-track levitation systems is that the magnetic drag rises to a peak in the low speed region, nominally at about $50 \mathrm{~km} / \mathrm{hr}$ and then decreases, being proportional to (velocity) ${ }^{-1 / 2}$ in the high velocity limit. Magnetic lift, on the other hand, rises to a maximum somewhere in this same speed range and then remains constant as the speed increases. Since operating costs for a given cargo weight will tend to scale inversely with lift to drag ratio, there is considerable interest in providing very high speed magnetic levitation systems. Aerodynamic drag is proportional to (velocity) ${ }^{2}$ and becomes comparable with magnetic drag somewhere in the neighborhood of $200 \mathrm{~km} / \mathrm{hr}$. This leads to the suggestion that perhaps the train should run in an evacuated or partially evacuated tunnel to reduce aerodynamic drag and take advantage of the high lift-to-drag ratios obtainable at high speeds.

The optimum configuration of the eddy-current track structure remains to be determined. Powell and Danby (1966) have suggested a "null flux" scheme giving lift to drag ratios in the range 100 to 500 and allowing reasonable clearance $(\approx 20 \mathrm{~cm})$ between the vehicle and track structure, but requiring a fairly complex track structure and giving a rather stiff suspension. Kolm (1972) favors a much simpler, trough-like continuous-sheet track giving a suspension much less sensitive to minor track irregularities, but lift-to-drag ratios not 


\section{MAGNETIC SUSPENSION - Repulsive}

THE SUPERCONOUCTING MAGNETS ABOARO THE MOVING TRAIN ARE REPELLEO BY EOOY-CURRENTS IN THE TRACK CIRCUITS.

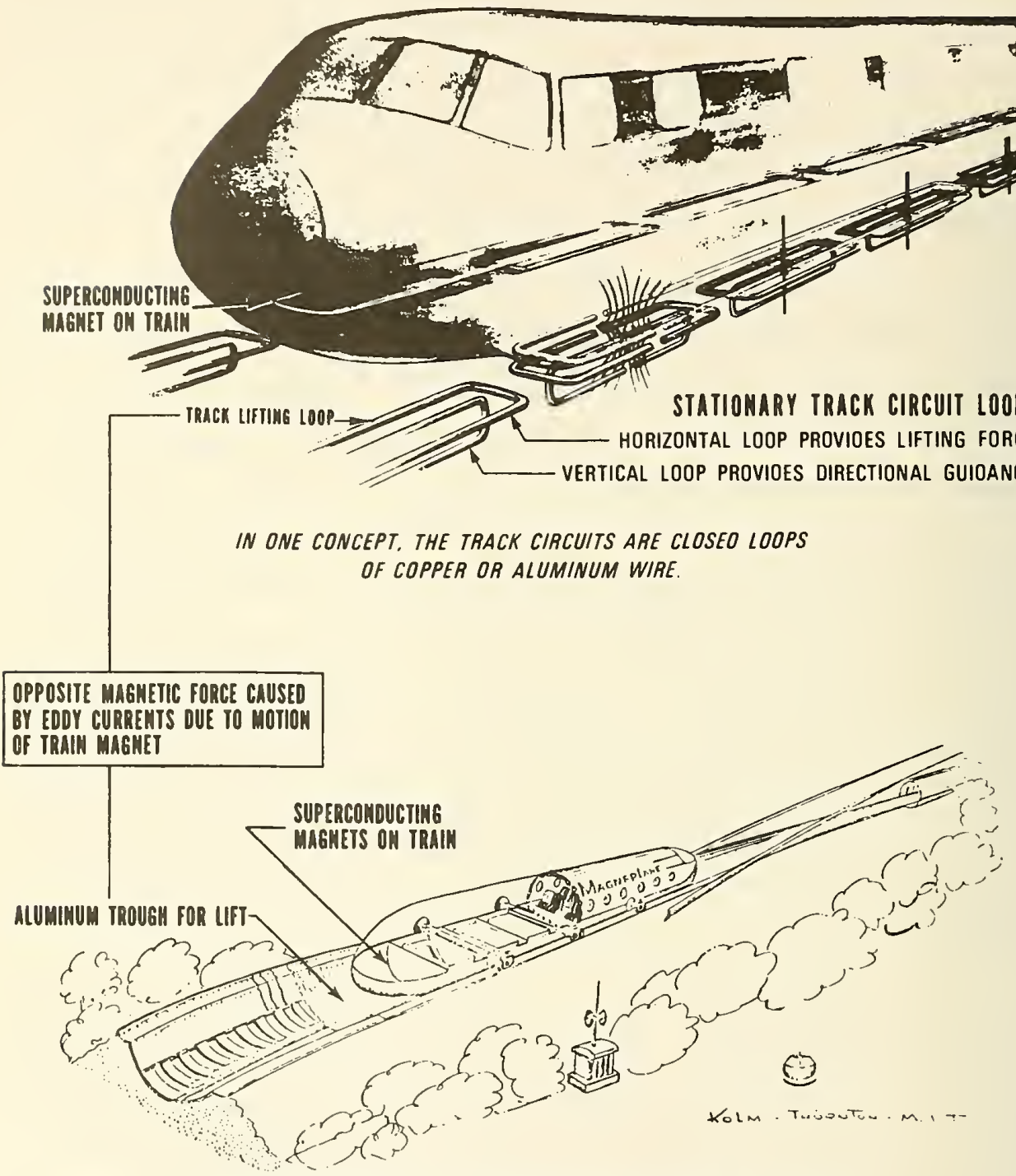

IN ANOTHER CONCEPT. A CONTINUOUS CURVEO SHEET OF ALUMINUM IS USEO INSTEAO OF THE TRACK CIRCUIT LOOPS.

Figure 3. Schematic diagram of two possible repulsive-suspension systems employing superconducting magnets. 
much more than 10 or 20. The Japanese are experimenting with a "ladder-track" which gives lift-to-drag ratios comparable with the sheet track. Guderjahn and Wipf (1971) suggest that a hybrid system employing some iron in the eddy current track may be advantageous. The lift-to-drag ratios obtainable with the null-flux system at high speed in an evacuated tunnel would be truly remarkable: Powell and Danby estimate that such a vehicle with a lift-to-drag ratio of 500 would coast (without propulsive power) 640 kilometers while its speed dropped from 960 to $800 \mathrm{~km} / \mathrm{hr}$. This is equal to the distance from Washington, D.C. to Boston, and more than the length of the Tokaido high speed rail line. One can conceive of using this fact to minimize the propulsive requirements of an active-track system. A further advantage of high lift-to-drag ratios comes from the reduced total energy requirement for transportation on a national scale--an important factor. Selection of an optimum track configuration depends on a wide number of system and operational parameters.

Of all the proposals and work on superconducting levitation systems, the superconducting coils themselves receive relatively little attention since their use seems straightforward. The ambient magnetic fields experienced by the magnet windings will be in the neighborhood of $3 \mathrm{~T}$ (30 kilogauss), somewhat lower than those generally met in other superconducting magnet applications. Current densities in the coils are in the range $2 \times 10^{4}$ to $5 \times 10^{4} \mathrm{~A} / \mathrm{cm}^{2}$, higher than standard practice for high field magnets, but consistent with the smaller ambient fields expected for this application. The magnets would be operated in the persistent current mode, so that the levitation would not fail if an external power supply were to fail; such persistent mode operation is also within the state of the art. In order to hold the weight of the magnet to a reasonably low value, the modern dynamically-stabilized, twisted multifilament $\mathrm{NbTi}$ conductors without too much copper 
would probably be used. If track irregularities should cause too high an a.c. ripple at the magnet, these could be shielded out by an eddy current shield so that operational losses would be low.

A concise summary of the present situation comes from Dr. John Harding (1971) of the ORDD: "All aspects of the repulsive superconducting suspension have by now been evaluated in sufficient depth that it can be stated that the system is technically feasible. It cannot be faulted on any single factor, such as cryogenics, superconductivity, or magnetic shielding. If the superconducting magnetic suspension is abandoned, it will have to be because of a combination of factors and not any particular shortcoming."

3. STATE-OF-THE-ART IN THE U.S. OF MAGNETIC SUSPENSION

The U.S. Department of Transportation has a strong, long range interest in magnetic levitation through its Office of Research, Development and Demonstration (ORDD). In early 1971, Ford and SRI were the successful bidders for an ORDD contract oriented to determine whether magnetic levitation is a practical alternative to wheels or air cushions for suspending and guiding high speed ground vehicles. These companies are contributing funds approximately matching those of ORDD to their projects for a total effort of about one-half million dollars. Ten different bids for these contracts were received by ORDD.

These contracts at Ford and SRI were renewed in March 1972 at about the same funding rate. In 1972, also, Kolm and Thornton of MIT recieved funding from NSF for studies of what they call the Magnaplane. This is a rather specific system intending to utilize superconducting magnets moving above a sheet aluminum track and linear synchronous propulsion. 
A small private company was formed about a year ago to try to build a small full-scale system, but it has given up this approach at this time.

\section{FOREIGN PROGRAM PLANS}

The ORDD maintains close contacts with these various national high speed ground transportation programs, and there is every reason to believe that technical information exchange is unimpeded.

Work is going on in Japan, Germany, and Canada. The Japanese effort is the largest, amounting to $\$ 10$ million per year, most of which will be for construction and operation of a 400 meter superconducting magnetic levitation test track. They had a small (four passenger size) vehicle in operation on the track in October of this year (1972), levitated by superconducting magnets running above discreet coils in the track. They are considering primarily active track propulsion, which avoids the problem of pickup of electrical power by the fast moving vehicle. Future tests of linear synchronous propulsion are anticipated as an alternative to the linear induction motor.

In Japan, the decision is of some urgency inasmuch as capacity on the New Tokaido Line (NTL) between Tokyo and Osaka is expected to reach saturation by 1980 . In 1970, 85 million intercity passengers were carried on the NTL express trains at a profit of over $\$ 300$ million. During the busiest hour, nine NTL expresses with a combined capacity of 10,460 passengers leave Tokyo for Osaka. Rather than expand the present system for additional capacity, the Japanese National Railways (JNR) is directing its research toward magnetically levitated trains which can convey passengers from Tokyo to Osaka in just over one hour. 
The German Ministry of Transport is funding both attractive and repulsive magnetic suspension vehicle programs. The attractive rail program, utilizing conventional electromagnets and a very small magnet-to-rail clearance, has produced two test vehicles, one at Messerschmitt-Bolkow Blohm (MBB) and the other at Krauss-Maffei (KM). Similar conceptually, these vehicles differ in the techniques chosen to provide guidance, stability, and vibration isolation of the passenger compartment: The repulsive suspension program, utilizing superconducting magnets, has been funded more recently at Seimans, and has not yet produced any models comparable with the MBB and KM vehicles.

The Canadian Department of Transport has just initiated a study of superconductive systems for high speed ground transportation. The activity will be conducted at the Institute for Guided Ground Transport at Queens University in Kingston, Ontario. The Canadian program will concentrate on superconducting magnet design, the cryogenics problems, and the development of a linear synchronous motor concept deriving thrust from switched powered coils in the guideway.

Tests and decisions made outside of the USA will undoubtedly have an influence over our own decisions scheduled in the late 1970's. The Japanese test track studies will undoubtedly be an important input to the U.S. decision-making process. The Japanese are currently about two years ahead of the U.S. towards the goal of a working system, though the U.S. appears to have a broader base of studies of system alternatives. The Japanese are putting larger sums of money into their studies than the U.S., and they hope to have a superconducting levitated train running between Tokyo and Osaka by 1980 . 


\section{PROPULSION}

Possible propulsion systems to be used with magnetic levitation are summarized in table 3. Only the linear electric motors are being seriously considered by any of major world-wide studies at this time, though the aerodynamic propulsion systems have been mentioned as possibilities. The linear electric motors have the great advantage of being quiet and pollution-free, and capable of operation in an evacuated tunnel. Vehicle-mounted superconducting coils for a linear induction motor could conceivable provide both propulsion and lift, even at zero speed. This can be done through the use of a.c. powered superconducting coils (Richards and Tinkham, 1970), or rotating d.c. coils providing a magnetic paddle wheel or propeller effect (Borcherts, 1972). Alternating current losses in superconducting coils would have to be decreased by a dramatic factor before the a.c. system becomes feasible. Linear synchronous propulsion requires only that power be fed into stationary coils in track in the immediate vicinity of the vehicle, such that the field of these stationary coils pushes on the superconducting magnets in the vehicle. Power must be supplied to each succeeding track coil in synchronism with the vehicle movement, and variable frequency power supplies will have to be developed to make this scheme practicable.

\section{SOME CRYOGENIC TECHNICAL PROBLEMS}

Cryogenic technology will be essential to the superconducting levitation system. This technology is well in hand for the purposes of laboratory and test model development. However, a full-scale working transportation system will demand a degree of reliability and serviceability of the cryogenic components which is beyond present standards, 
Table 3. Propulsion System

Method

Advantage

Requires no development; works independently of vehicle clearance.

Disadvantage

Noise and fumes: very high vehicle weight since fuel must be carried. Could not be used in evacuated tunnel.

Linea $r$ induction motor in the vehicle.
Does not require variable frequency input power; allows easy control of starting and stopping (not true, however, if used also for levitation: Richards and Tinkham, 1970) compact propulsion unit. Works in vacuum if necessary; no noise.

\section{Requires small vehicle to} track clearance ( $1-2 \mathrm{~cm})$; transmission of power from a line to the high speed vehicle is very difficult.

\begin{abstract}
Linear synchronous motor in the track.
\end{abstract}

Allows high vehicle clearance $(20 \mathrm{~cm})$, and lower vehicle weight; a ppears to permit safe operation of closely spaced vehicles; no power transmission to the vehicle is required. Works in vacuum if necessary; no noise.
Requires variable frequency power services and complicated controls to activate that section of track which the vehicle occupies, and make a smooth transition to the next section.

\section{Aerodynamic: partially evacu- ated tunnel ahead of the vehicle.}

Power source can be conveniently separated from the vehicle or track; may be required in any case for speeds above $500 \mathrm{~km} / \mathrm{hr}$.
Low efficiency: difficult to control precisely or with multiple units; requires low vehicle to tunnel clearance. Requires alternate technique for starting from an unevacuated station.

\footnotetext{
Impulse-jet:

track-based

air jets are

activated as the

train passes.

(Mouritzen, 1972)
}
Convenient location of con- ventional power sources (turbo-compressors) at intervals along the track. Can utilize schemes of energy storage in com- pressed air. High vehicle- to track clearance.

Could not be used in an evacuated tunnel. Noisy, though not as much so as propellers or jet engines. Low efficiency, $20-25 \%$. 
and must be considered carefully. There is no reason to believe that the scale-up in technology cannot be done successfully, but there are areas where additional knowledge must be developed in order to do the job with assurance. These are discussed here briefly.

\subsection{Helium Refrigeration}

Maintenance of the superconducting magnet at $4 \mathrm{~K}$ for weeks or months on end will be a necessity for superconducting levitation. Some suggest that a liquid helium supply be simply replenished from a central storage reservior at convenient intervals, much as one now puts ice on a train. However, the drain on the earth's helium resource would be very large if the boil-off helium were not collected, assuming a large national train and track system. It is likely that on-board refrigeration will be superior from an operational standpoint. However, refrigerator reliability would have to be extended over that available at this time. This would call for a substantial effort, especially to increase the mean time between failure of room-temperature refrigeration compressors. The Refrigerator Sub-Task of the DoC-NBS Presidential Initiative in Cryogenics for the Electrical Industry has as its goals increasing refrigerator reliability and optimizing refrigerator efficiency. Thus, this technology is directly transferable from the DoC program.

\subsection{Materials}

The availability of reliable superconducting coils, which was initially thought to be the major drawback of the induced levitation schemes, is now considered to be well within the present state-of-the-art. Nonetheless, there are unknown problems of building, supporting, and maintaining the superconducting coils in daily operation. For instance, the forces on the superconducting magnet at $4 \mathrm{~K}$ must be transmitted to the vehicle by some sort of solid connection which must not increase 
the helium heat load to unworkably high values. Composite materials, such as the fiber reinforced plastics, seem to excel for this application, and in fact have been suggested in one form or another by all the superconducting levitation papers which have touched this topic.

A major problem which this brings up is the almost total lack of fatigue studies on materials of all kinds at low temperatures, as well as more general lack of properties data: expansion coefficients (generally anisotropic with oriented fibers), complete stress-strain data as a function of temperature, sensitivity to notches or cracks, aging effects for extended service, thermal conductivity, etc. Completely unknown at this time is the effect of fatigue upon the electromagnetic properties of the system. These material problems are congruent with those of the DoC-NBS program on superconducting generators.

\section{FUTURE DEVELOPMENT}

The late 1970's appear to be the U.S. target date for selection of the optimum levitated-vehicle system for major development in this country. Tests and evaluations of all potential systems - TACV, attractive rail, repulsive superconducting, and possibly even advanced wheel concepts - should be complete by then. No one system has a clear advantage at this time, in that all except the wheel appear to be able to provide vehicle transportation at speeds up to $300 \mathrm{mph}(500 \mathrm{~km} / \mathrm{hr})$ without relying on yet-to-come technological breakthroughs. It appears most probable that selection will be based upon combinations of system parameters, using criteria which are not clearly defined and ranked at present. Examples of such criteria include cost, safety, ease of switching, control of close-spaced vehicles, the need for speed as compared to the need for convenient stop and start service operation, 
possible extension to speeds higher than $300 \mathrm{mph}(500 \mathrm{~km} / \mathrm{hr})$, on-board vehicle power requirements, liquid helium service requirements, freedom from noise adjacent to the track, freedom from fuel combustion products along the track, allowable development time scale, availability of large blocks of electric power, etc.

In these days of concern over environmental problems, it appears that the magnetic levitation systems may be favored for being more pollution-free than the TACVs. Some DoT engineers believe that the superconducting system could prove superior to the attractive rail system even if low-cost reliable control systems are developed for the servo-controlled electromagnet system. The major cost in a total system will be in the production, installation and maintenance of the guideway, they believe. Because the superconducting system works with a larger gap between vehicle and guideway, it would allow for lower costs in manufacture, installation and maintenance.

The need for advanced forms of ground transportation seems compelling as evidenced by government-sponsored research programs in four major countries including ours. The U.S., which may make the largest use of such a system in the long run, may be contributing a disproportionately small share of the research and development cost for magnetic levitation, about $\$ 0.5$ million out of a world wide spending of over $\$ 10$ million per year.

A high speed ground transportation system represents a gigantic capital investment. The $515 \mathrm{~km} \mathrm{New} \mathrm{Tokaido} \mathrm{Line,} \mathrm{a} \mathrm{high} \mathrm{speed} \mathrm{conven-}$ tional rail link between Tokyo and Osaka, had cost about $\$ 1.1$ billion when service was initiated in October 1964. The estimated cost of a proposed Tracked Air Cushion Vehicle system offering 2.3 hour travel time for the 650 miles $(400 \mathrm{~km})$ between Washington and Boston is $\$ 2.7$ billion. 
The degree of interest, as measured by the international scale of the research on the problem to date, suggests strongly that a positive decision to proceed with a full scale program will be made in the U.S. in the late $1970^{\prime} \mathrm{s}$, when comparative merits of the alternative systems will have been evaluated. Superconducting levitated vehicles are in contention, but lagging over other levitation systems in the degree of development work to date. The chances that a superconducting levitation system will be selected and developed in the U.S. are impossible to assess, being dependent on complex technical, economic, and social forces, but it is not unreasonable to believe that they are in the $10 \%$ to $50 \%$ range.

A decision to proceed with a full-scale superconducting levitation system would have major impact in the cryogenics industry. At the present time, annual sales in this diverse industry are about $\$ 1.5$ billion, of which only a very small fraction is derived from superconducting and liquid helium temperature components. In order to service a large transportation system with many superconducting levitated vehicles running continuously over a wide geographical area, it is not unreasonable to believe that annual sales of superconducting components and support equipment could reach the neighborhood of several hundred million dollars. It would be appropriate to tackle the major developmental research in the cryogenics program at an early stage. 


\section{REFERENCES}

Borcherts, R. H., "Mathematical Analysis of 'Permanent' Magnet Suspension Systems," J. Appl. Phys. 42, 1528 (1971).

Borcherts, R. H., to be published (1972).

Clark, A. F., "Combination of power transmission line and an active track for a magnetically suspended high speed train, "to appear in J. Appl. Phys. (Aug 1972).

Coffey, H. T., Barbee, T. W., and Chilton, F., "Magnetic suspension and guidance of high speed vehicles," Conf. on Low Temperatures and Electric Power, IIR Annexe, p. 311 (1969).

The Economist, p. 55 (May 8, 1971).

Guderjahn, C. A., and Wipf, S. L., "Magnetic Suspension and guidance for high speed trains by means of superconducting magnets and eddy currents," Adv. in Cryogenic Eng. 15. (1969).

Guderjahn, C. A., and Wipf, S. L., "Magnetically levitated trans portation, "Cryogenics 11, 171 (1971).

Harding, J. T., "Progress in magnetic suspension applied to high speed ground transportation," presented at the 17th Annual Conf. on Magnetism and Magnetic Materials, Chicago, Illinois (Nov 1971).

Hartke, Senator Vance, "Replacing our hodge-podge transportation," reported in Astronautics \& Aeronautics, 10, 52 (Feb 1972).

Kerr, C., and Lynn, C. "Roller road", Westinghouse Engineer (Mar 1961).

Mouritzen, G., "Impulse-jet transportation system," Mech. Eng., p. 12 (Feb 1972).

Pohlgreen, G. R., "Guided land transport," Proc. Inst. Mech. Engrs. 181,145 (1966).

Powell, J. R., "The magnetic road: a new form of transport," paper 63-RR4, ASME Railroad Conference (Apr 1963). 
Powell, J. R., and Danby, G. T., "High speed transportation by magnetically suspended trains, "ASME paper 66-WA/RR-5, Winter Annual Meeting of ASME, New York (1966), also published in Mech. Eng. 89, 30 (1967).

Powell, J. R., and Danby, G. T., "Magnetic suspension for levitated track vehicles," Cryogenics 11, 192 (1971).

Richards, P. L., and Tinkham, M., "Magnetic suspension and propulsion systems for high speed transportation," J. Appl. Phys. $\underline{43}, 2680$ (1972).

Strobridge, T. R., "Refrigeration for superconducting and cryogenic systems," IEEE Trans. Nucl. Sci. NS-16. (Proc. 1969 Particle Accelerator Conf., Washington D. C. (Mar 1969). 
2. Gov't Accession No.

Some Applications of Cryogenics to High Speed Ground Transportation

\section{AUTHOR(S)}

V. D. Arp, A. F. Clark and T. M. Flynn

\section{PERF ORMING ORGANIZATION NAME AND ADDRESS}

NAT IONAL BUREAU OF STANDARDS, Boulder Labs DEPARTMENT OF COMMERCE WASHINGTON, D.C. 20234

\section{Sponsoring Organization Name and Address}

Same as Item 9
3. Recipient's Accession No.

5. Publication Date

February 1973

6. Performing Organization Code

8. Performing Organization

10. Project/Task/Work Unit No.

$$
2750101
$$

11. Contract/Grant No.

13. Type of Report \& Period Covered

14. Sponsoring A gency Code

\section{SUPPLEMENTARY NOTES}

16. ABSTRACT (A 200-word or less factual summary of most significant information. If document includes a significant bibliography or literature survey, mention it here.)

The current status (December 1972) of worldwide research on high speed ground transportation techniques is reviewed. Particular attention is given to studies of magnetic levitation using superconducting magnets, including comparis on with alternative magnetic techniques and with air suspension systems. Superconducting levitation appears to be a strong contender in the U.S. Department of Transportation hopes to select in the late $1970^{\prime}$ s the best of the possible levitation techniques for subsequent advanced development. Cryogenic engineering research needed in support of major development of a superconducting levitated system is identified.

17. KEY WORDS (Alphabetical order, separated by semicolons)

Levitation; magnetic suspension; materials fatigue data; refrigeration; superconducting magnets; transportation.

\begin{tabular}{|c|c|c|}
\hline 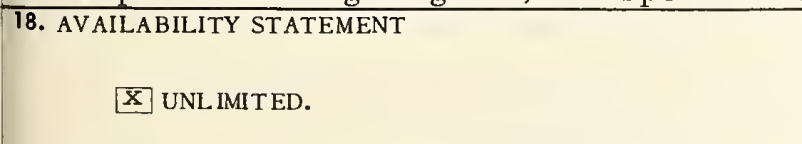 & $\begin{array}{l}\text { 19. SECURITY CLASS } \\
\text { (THIS REPORT) } \\
\text { UNCL ASSIFIED }\end{array}$ & $\begin{array}{l}\text { 21. NO. OF PAGES } \\
29\end{array}$ \\
\hline $\begin{array}{l}\square \text { FOR OF FICIAL DISTRIBUTION. DO NOT RELEASE } \\
\text { TO NTIS. }\end{array}$ & $\begin{array}{l}\text { 20. SECUR ITY CLASS } \\
\text { (THIS PAGE) } \\
\text { UNCL ASSIFIED }\end{array}$ & $\begin{array}{r}\text { 22. Price } \\
.35\end{array}$ \\
\hline
\end{tabular}



PERIODICALS

JOURNAL OF RESEARCH reports National Bureau of Standards research and development in physics, mathematics, and chemistry. Comprehensive scientific papers give complete details of the work, including laboratory data, experimental procedures, and theoretical and mathematical analyses. Illustrated with photographs, drawings, and charts. Includes listings of other NBS papers as issued.

Published in two sections, available separately:

\section{- Physics and Chemistry (Section A)}

Papers of interest primarily to scientists working in these fields. This section covers a broad range of physical and chemical research, with major emphasis on standards of physical measurement, fundamental constants, and properties of matter. Issued six times a year. Annual subscription: Domestic, $\$ 17.00$; Foreign, \$21.25.

\section{- Mathematical Sciences (Section B)}

Studies and compilations designed mainly for the mathematician and theoretical physicist. Topics in mathematical statistics, theory of experiment design, numerical analysis, theoretical physics and chemistry, logical design and programming of computers and computer systems. Short numerical tables. Issued quarterly. Annual subscription: Domestic, $\$ 9.00$; Foreign, $\$ 11.25$.

\section{TECHNICAL NEWS BULLETIN}

The best single source of information concerning the Bureau's measurement, research, developmental, cooperative, and publication activities, this monthly publication is designed for the industry-oriented individual whose daily work involves intimate contact with science and technology-for engineers, chemists, physicists, research managers, product-development managers, and company executives. Includes listing of all NBS papers as issued. Annual subscription: Domestic, $\$ 6.50$; Foreign, $\$ 8.25$.

\section{NONPERIODICALS}

Applied Mathematics Series. Mathematical tables, manuals, and studies.

Building Science Series. Research results, test methods, and performance criteria of building materials, components, systems, and structures.

Handbooks. Recommended codes of engineering and industrial practice (including safety codes) developed in cooperation with interested industries, professional organizations, and regulatory bodies.

Special Publications. Proceedings of NBS conferences, bibliographies, annual reports, wall charts, pamphlets, etc.

Monographs. Major contributions to the technical literature on various subjects related to the Bureau's scientific and technical activities.

National Standard Reference Data Series. NSRDS provides quantitative data on the physical and chemical properties of materials, compiled from the world's literature and critically evaluated.

Product Standards. Provide requirements for sizes, types, quality, and methods for testing various industrial products. These standards are developed cooperatively with interested Government and industry groups and provide the basis for common understanding of product characteristics for both buyers and sellers. Their use is voluntary.

Technical Notes. This series consists of communications and reports (covering both other-agency and NBS-sponsored work) of limited or transitory interest.

Federal Information Processing Standards Publications. This series is the official publication within the Federal Government for information on standards adopted and promulgated under the Public Law 89-306, and Bureau of the Budget Circular A-86 entitled, Standardization of Data Elements and Codes in Data Systems.

Consumer Information Series. Practical information, based on NBS research and experience, covering areas of interest to the consumer. Easily understandable language and illustrations provide useful background knowledge for shopping in today's technological marketplace.

\section{BIBLIOGRAPHIC SUBSCRIPTION SERVICES}

The following current-awareness and literature-survey bibliographies are issued periodically by the Bureau:

Cryogenic Data Center Current Awareness Service (Publications and Reports of Interest in Cryogenics). A literature survey issued weekly. Annual subscription: Domestic, $\$ 20.00$; foreign, $\$ 25.00$.

Liquefied Natural Gas. A literature survey issued quarterly. Annual subscription: $\$ 20.00$.

Superconducting Devices and Materials. A literature survey issued quarterly. Annual subscription: $\$ 20.00$. Send subscription orders and remittances for the preceding bibliographic services to the U.S. Department of Commerce, National Technical Information Service, Springfield, Va. 22151.

Dlectromagnetic Metrology Current Awareness Service (Abstracts of Selected Articles on Measurement Techniques and Standards of Electromagnetic Quantities from D-C to Millimeter-Wave Frequencies). Issued monthly. Annual subscription: $\$ 100.00$ (Special rates for multi-subscriptions). Send subscription order and remittance to the Electromagnetic Metrology Information Center, Electromagnetics Division, National Bureau of Standards, Boulder, Colo. 80302.

Order NBS publications (except Bibliographic Subscription Services) from: Superintendent of Documents, Government Printing Office, Washington, D.C. 20402. 
OFFICIAL BUSINESS

Penalty for Privats Use, $\$ 300$ 